\title{
Metallic foreign body adjacent to the round window: a rare cause for chronic tympanic membrane perforation with hearing loss
}

\author{
Samuel Robert Leedman 다, ' Jafri Kuthubutheen ${ }^{2}$
}

${ }^{1}$ Department of Otolaryngology Head and Neck Surgery, Fiona Stanley Hospital, Murdoch, Western Australia, Australia ${ }^{2}$ School of Medicine, The University of Western Australia, Perth, Western Australia, Australia

Correspondence to Dr Samuel Robert Leedman; samleedman@gmail.com

Accepted 7 May 2021

Check for updates

(C) BMJ Publishing Group Limited 2021. No commercial re-use. See rights and permissions. Published by BMJ.

To cite: Leedman SR, Kuthubutheen J. BMJ Case Rep 2021;14:e240106. doi:10.1136/bcr-2020 240106

\section{SUMMARY}

Welding injuries to the tympanic membrane (TM) or middle ear are rare but can cause significant damage. These injuries occur when a hot spark or molten slag drops directly into the external auditory canal and through the action of gravity (because the ear is upright during such an injury), then risks burning through the TM. This can lead to a multitude of adverse consequences including chronic TM perforation, secondary purulent otorrhoea, facial palsy, taste disturbance, vertigo and hearing loss. We present the case of a welding injury to the right TM, resulting in a chronic perforation and hearing loss. The patient required surgical intervention for removal of the metallic foreign body and repair of the TM. The patient obtained a good surgical result with no sensorineural hearing loss. This is a preventable occupational injury, which can be avoided by use of ear protection and increased awareness of this potential risk.

\section{BACKGROUND}

Welding injuries to the tympanic membrane (TM) or middle ear caused by hot sparks or molten slag are rare but can cause significant damage. These injuries occur when the spark or slag drops directly into the external auditory canal (EAC) and burns a hole through the TM. A number of important structures can be injured including the ossicles, facial nerve, chorda tympani nerve and potentially the labyrinth. This can lead to a host of consequences including chronic TM perforation and purulent otorrhoea, facial palsy, taste disturbance, vertigo and deafness. There are only four reported cases of this kind of injury in the international literature, with varying levels of injury severity and resultant morbidity. ${ }^{1-3}$

We present the case of a welding injury to the right TM, resulting in a chronic perforation and hearing loss. This is a preventable occupational injury, which can be avoided by use of ear protection and increased awareness of this potential risk.

\section{CASE PRESENTATION}

A 60-year-old man presented to the emergency department with severe burning pain in his right ear. He had been using an 'Oxy Torch' soldering iron on the underside of his semitrailer earlier that day. $\mathrm{He}$ was lying on his left side directly underneath the welding site and was not wearing ear protection. A spark of molten hot steel came off from the welding site and fell directly into the patients right EAC. He felt immediate severe burning pain to the right ear with associated loud 'fire cracker' like sounds, hearing loss and fullness. He poured cool tap water down the right EAC to some relief of the burning discomfort. He denied any vertigo or haemifacial weakness, but did report minor taste disturbance. On examination, the right EAC skin was healthy but with singed hairs and he had a $10 \%$ central anteroinferior TM perforation. He had no nystagmus and normal facial nerve function. He was provided analgesia and referred to the ear, nose and throat (ENT) surgery outpatient clinic.

Due to significant waitlist for outpatient clinics, the patient was first seen in the ENT rooms 8 weeks after initial presentation to the emergency department. On serial review in the outpatient clinic the patient described no ongoing pain. He suffered two ear infections within the first month after the injury. Both were treated to resolution with topical antimicrobial (ciprofloxacin) ear drops. After this time, he complied with strict dry ear precautions and had no further infections. He described a 'hollow' sensation of the right ear though had subjectively normal hearing, struggling only in crowded or loud environments with sound differentiation. Right-sided high pitched non-pulsatile tinnitus affected him intermittently and was precipitated particularly by cold weather.

He was otherwise fit and well, with a medical history including only hypertension and raised cholesterol for which he was on irbesartan, verapamil and a statin. He had no known drug allergies and was a nonsmoker, working full time as a long-haul truck driver and demolitions technician.

\section{INVESTIGATIONS}

The patient had a CT scan of the temporal bones in the days following the injury. This demonstrated a $1.7 \mathrm{~mm}$ spherical metallic foreign body situated in the sinus tympani and abutting the round window membrane (figure 1). There was no evidence of ossicular injury and the bony labyrinth was normal. The middle ear was opacified though the mastoid was well pneumatised. The TM perforation was also noted. The left temporal bone was normal. An MRI scan was not performed in view of the metallic nature of the foreign body.

A pure tone audiogram 8 weeks after the injury showed a mild conductive hearing loss on the right side $(30 \mathrm{~dB}$ hearing threshold) at all levels except $4000 \mathrm{~Hz}$ where the loss was more pronounced $(60 \mathrm{~dB})$. There was no sensorineural hearing loss. The left ear hearing was normal. Tympanogram 


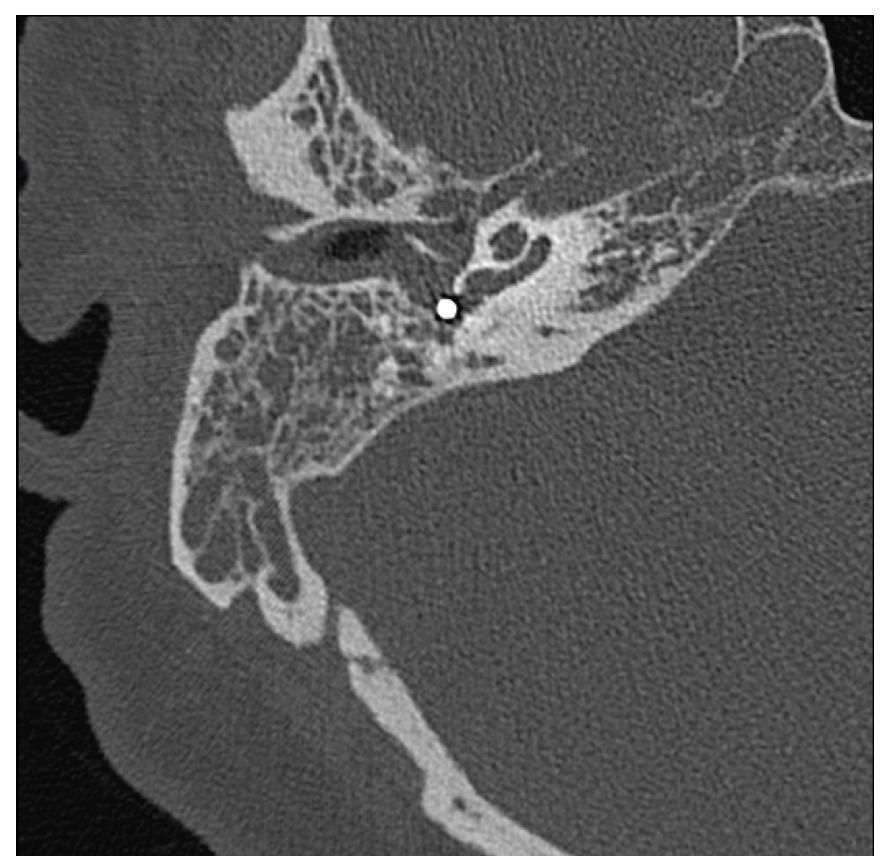

Figure 1 Axial CT slice of the right temporal bone acutely postinjury demonstrating rounded metallic foreign body abutting the round window with mastoid and middle ear effusion.

revealed type B large volume on the right, consistent with a TM perforation and type A on the left, reflective of a normal TM and an aerated middle ear cavity. A repeat CT scan of the temporal bone closer to the time of surgery showed that the acute middle ear and mastoid opacification had resolved and that the foreign body had not moved (figure 2). This was performed prior to surgical intervention and in order to prepare for potential round window or labyrinthine involvement.

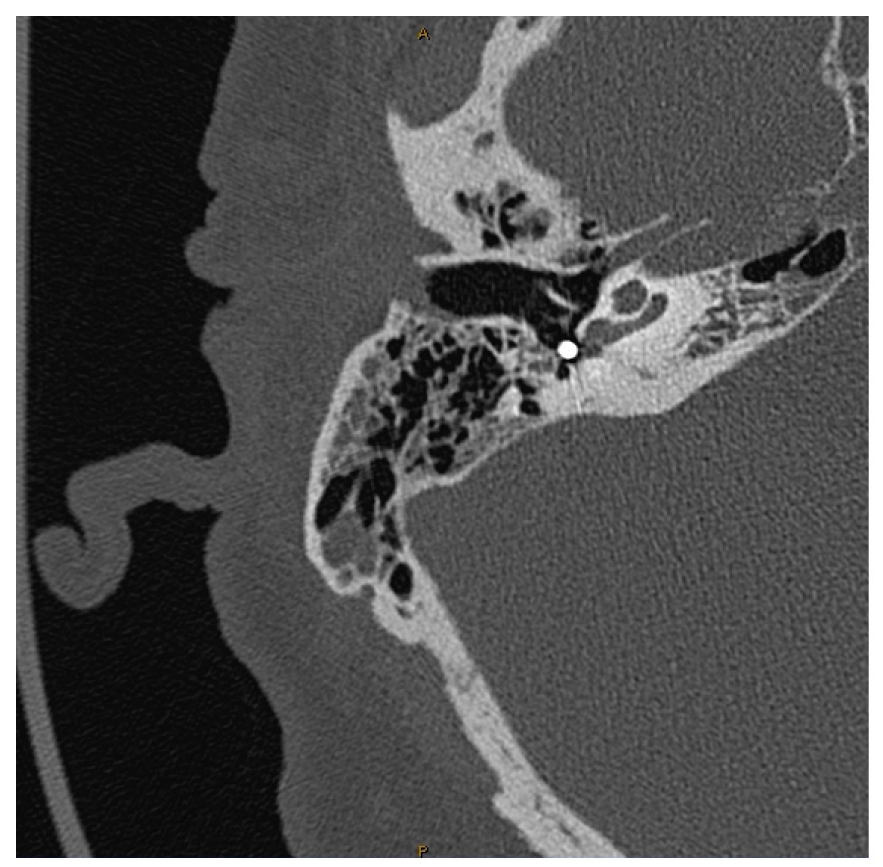

Figure 2 Axial CT slice of the right temporal bone 3 months later demonstrating rounded metallic foreign body in unchanged position and resolution of mastoid and middle ear effusion.

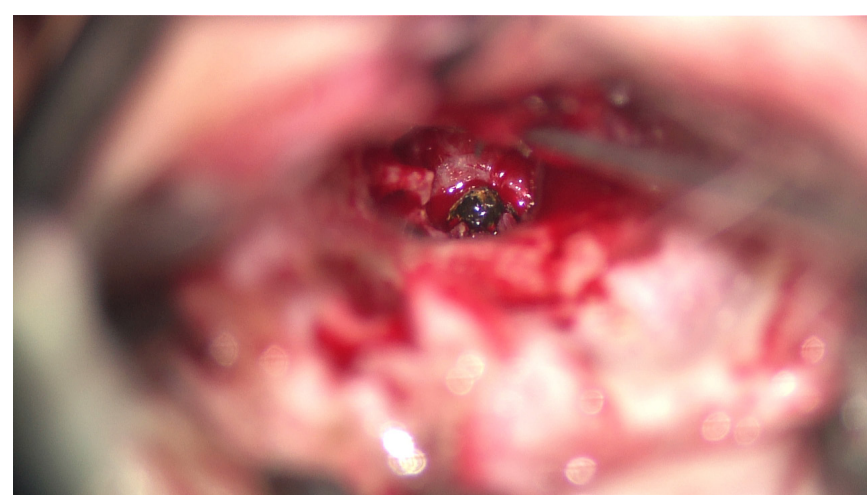

Figure 3 Intraoperative image demonstrating the rusting metallic foreign body in the middle ear space, prior to removal.

\section{TREATMENT}

The right-sided dry TM perforation persisted on serial examination with associated conductive hearing loss. Given the rare nature of this case, it was discussed at a multidisciplinary otology radiology meeting at the tertiary treating hospital. The decision was made to proceed with an endaural approach myringoplasty and removal of the middle ear metallic foreign body on an urgent elective basis. The clearing of the middle ear and mastoid opacification on CT indicated that an emergent operation was not necessary.

The patient proceeded to surgery within 3 weeks of the initial ENT review. An endaural approach was undertaken. The tympanomeatal flap was elevated and a posterior atticotomy was performed in addition to removal of bone over the posterosuperior bony meatal wall. A posterior canalplasty was performed in addition to this access. This was done to identify the inferior portion of the body of the incus, long process of incus and incudostapedial joint as well as the stapes. The stapes superstructure, pyramidal process and stapedial tendon were identified intraoperative. The foreign body was seen just inferior to the round window niche (figure 3 ) with associated inflammatory tissue. The middle ear mucosa was otherwise largely normal. The chorda tympani nerve was noted to be traumatised and could not be preserved. The foreign body was then carefully removed off the round window niche with no breach of the round window membrane or perilymphatic leak. Myringoplasty was performed using a tragal perichondrium graft. The patient had an uncomplicated postoperative course with no acute imbalance or sensorineural hearing loss. He did report right sided dysgeusia postoperatively. He did not require ossicular chain reconstruction and recovered well postoperative, discharged home the following day.

\section{OUTCOME AND FOLLOW-UP}

The patient was seen again in the outpatient clinic 2 weeks postoperatively. At this visit, his endaural wound had healed and the TM was intact. Clinically the patient reported no imbalance and a bone conduction audiogram revealed preserved bone conduction thresholds indicating no sensorineural hearing loss. He reported minor improvement of his right sided dysgeusia. The patient was allowed to return to work while wearing ear protection.

\section{DISCUSSION}

Welding injuries to the TM and middle ear due to hot sparks or molten slag can cause permanent and severe damage to hearing and facial nerve function. Management of these injuries 
is surgical with removal of the foreign body, repair of the ear drum (myringoplasty) and reconstruction of the ossicular chain if required (tympanoplasty with ossicular chain reconstruction). The case presented is of an exceedingly lucky man who suffered only mild conductive hearing loss from his injury and had a positive outcome from surgical intervention with full recovery of his hearing and removal of the offending foreign body.

These injuries are very rare, there are only four other similar reported cases in the international literature. One case written by Keogh and Portmann describes a left TM drop welding injury which resulted in chronic TM perforation as well as suppuration due to chronic foreign body reaction. ${ }^{3}$ This presented a difficult perforation to surgically manage. Another case described a man with minimal symptoms or infection, and only mild hearing loss, despite severe ossicular chain damage, who underwent a successful tympanoplasty 6 months after his initial injury. ${ }^{2}$

\section{Learning points}

- Welding injuries to the tympanic membrane or middle ear caused by hot sparks or molten slag are rare but can cause significant damage and sequelae, including hearing loss and facial nerve injury.

- Management is typically surgical with removal of the foreign body, repair of the ear drum and reconstruction of the ossicular chain if required.

- These are preventable occupational injuries and are best avoided by the use of ear protection or earplugs and increased awareness of this rare but significant potential risk.
The other two described cases are similar, both of unfortunate patients who suffered facial nerve injury and one also with severe damage to the inner ear structures, both secondary to molten slag transtympanic welding injuries. ${ }^{1}$

Transtympanic thermal trauma caused by welding is a preventable occupational injury. This can best be avoided by metal workers with use of ear protection and increased awareness of this rare but significant potential risk. The inflammation and suppuration related to a rusting metal foreign body as well as the direct thermal injury to the TM and middle ear structures presents a unique surgical challenge to the otolaryngologist.

Contributors The authors were involved in clinical diagnosis and management of the case, performing a literature review and writing the manuscript. JK was responsible for the overall patient care and surgical procedure for this patient. He also assisted with editing the final manuscript. SRL is the primary author of the provided manuscript, with editing assistance from JK.

Funding The authors have not declared a specific grant for this research from any funding agency in the public, commercial or not-for-profit sectors.

Competing interests None declared.

Patient consent for publication Obtained.

Provenance and peer review Not commissioned; externally peer reviewed.

ORCID iD

Samuel Robert Leedman http://orcid.org/0000-0003-1876-3674

\section{REFERENCES}

1 Panosian MS, Wayman JW, Dutcher PO. Facial nerve paralysis from slag injury to the ear. Arch Otolaryngol Head Neck Surg 1993;119:548-50.

2 Eleftheriadou A, Chalastras T, Kyrmizakis D, et al. Metallic foreign body in middle ear: an unusual cause of hearing loss. Head Face Med 2007;3:23.

3 Keogh IJ, Portmann D. Drop weld thermal injuries to the middle ear. Rev Laryngol Otol Rhinol 2009;130:317-9.

Copyright 2021 BMJ Publishing Group. All rights reserved. For permission to reuse any of this content visit

https://www.bmj.com/company/products-services/rights-and-licensing/permissions/

BMJ Case Report Fellows may re-use this article for personal use and teaching without any further permission.

Become a Fellow of BMJ Case Reports today and you can:

- Submit as many cases as you like

- Enjoy fast sympathetic peer review and rapid publication of accepted articles

- Access all the published articles

- Re-use any of the published material for personal use and teaching without further permission

Customer Service

If you have any further queries about your subscription, please contact our customer services team on +44 (0) 2071111105 or via email at support@bmj.com.

Visit casereports.bmj.com for more articles like this and to become a Fellow 